\title{
Promoting Well-Being in School-Based Mentoring Through Basic Psychological Needs Support: Does It Really Count?
}

\author{
Francisco Simões $\cdot$ Madalena Alarcão
}

Published online: 11 April 2013

(C) Springer Science+Business Media Dordrecht 2013

\begin{abstract}
The main goal of this research was to assess whether satisfying basic psychological needs (BPN) in a Portuguese school-based mentoring (SBM) program improved the mentored students' well-being. One uncommon feature of this program was that the mentors were also teachers of the mentees. A two-wave experimental study design was implemented to compare the mentored $(n=157)$ and non-mentored students $(n=160)$. Surveys were completed twice, with a 6-month interval between time points 1 and 2 . The results indicate that SBM that was associated with increased support for BPN was the most effective condition for promoting academic well-being, particularly in terms of improving the mentored students' perceptions of their school environment. However, no significant differences between the mentored and non-mentored students were detected regarding personal well-being (e.g., psychological well-being) and social well-being (e.g., peer support). These findings suggest that the balanced support of BPN was important in this particular SBM program. This support and enduring mentoring relationships can facilitate the general improvement of the mentored students' well-being.
\end{abstract}

Keywords School-based mentoring · Basic psychological needs · Well-being

\section{Introduction}

Schools are increasingly committed to improving students' knowledge and well-being. This dual purpose is shared by different educational stakeholders and stems from the assumption that student performance depends on a wide array of cognitive, emotional and

\footnotetext{
F. Simões ( $\square)$

University of Coimbra, Canada da Francesa, 28, São Mateus da Calheta, Angra do Heroísmo, 9700-551 Açores, Portugal

e-mail: francisco.simoes@cipp-terceira.com

M. Alarcão

Faculty of Psychology and Educational Sciences, University of Coimbra, Rua do Colégio Novo, 3000 Coimbra, Portugal

e-mail: malarcao@uc.pt
} 
social factors (Durlak et al. 2011). As a result, school boards, teachers and researchers have made significant efforts not only to optimize teaching and learning conditions, but also to enhance social support for students, which may lead to increased well-being. Social support involves the provision of psychological and material resources to help others, such as students, to cope with the challenges of social relationships (Cohen 2004). Children and youth may benefit from social support in horizontal relationships (e.g., with peers) and in vertical relationships (e.g., with teachers) (Chu et al. 2010). The need to improve relationships between students and teachers is justified by the fact that the quality of social support provided by meaningful adults leads to higher levels of independence, persistence, social competence (Bergin and Bergin 2009) and well-being (Ciani et al. 2011; Véroneau et al. 2004). One of the most significant interventions implemented in schools to address the well-being of students is School-Based Mentoring (SBM). Therefore, the overriding purpose of this study is to understand how the well-being of mentored students may be influenced by the social support provided by teachers in their role as school mentors.

\subsection{Well-Being: Definitions, Conceptual Dimensions and Research Approaches}

The definition of well-being ranges from vague notions to relevant conceptual delimitations that convey specific meaning. Huta and Ryan (2010) generally define well-being as "one or more subjectively experienced states or evaluations of one's life that could be rated as desirable or undesirable such as positive affect, negative affect, life satisfaction, inspiration, awe, transcendence, sense of meaning, feeling carefree, and vitality" (p. 2). This and other current definitions of well-being may include emotional, social, behavioral, physical, economical or cultural components. Thus, well-being is a multidimensional notion, and its assessment must be grounded in different and complementary indicators (Linley et al. 2009). According to early conceptualizations, well-being had a cognitive component, related to subjective appraisals of satisfaction with one's life, and an affective component, associated with the positive or negative feelings arising from these subjective appraisals (Diener 1984). However, more recent definitions of well-being are broader and include judgments about life satisfaction, pro-social behavior and optimization in performance contexts, such as school or work (Diener 2009). The increasingly sophisticated definitions of well-being have led to two primary research approaches. The hedonic approach considers well-being in terms of happiness, pleasure or subjective well-being (Diener 1984). The eudaemonic approach focuses on the realization of human potential in the context of the individual's life that leads to optimal functioning (Deci and Ryan 2000). This latter perspective has given rise to a considerable amount of research dedicated to the comprehension of social support in order to improve well-being in schools and other environments (Deci and Ryan 2000; Reis et al. 2000; Véroneau et al. 2004).

\subsection{Social Support and Well-Being in Schools: From Teaching to Mentoring}

Previous research has demonstrated that a high level of social support delivered by teachers is associated with the students' well-being in terms of satisfaction with schooling (Randolph et al. 2010), an increased sense of belonging (Murray-Harvey 2010) and lower rates of victimization (Murray-Harvey and Slee 2006). In addition, supportive relationships with teachers are strongly associated with students' engagement at school and, at some level, an improvement in school grades (Roorda et al. 2011). Recently, the support from teachers and school staff was found to be more strongly associated with a student's overall wellbeing than support from parents or friends (Chu et al. 2010). 
The eudaemonic research approach to well-being has expanded to include the social support provided by adults in interventions in schools, such as SBM. The main feature of SBM is the creation of a significant, secure and long-lasting bond between non-familiar adults and vulnerable students (Russell 2007). The goals of SBM vary from program to program. However, SBM usually combines theoretical, methodological and practical principles in order to reduce the mentees' personal, social and/or academic deficits, promote their developmental potential in the same areas, or both (Karcher and Nakkula 2010; Lavigne et al. 2011).

SBM has been associated with the improvement of the mentees' personal well-being by an increase in self-esteem (Karcher 2008). Moreover, SBM has been linked to better social well-being in mentored students because it leads to more positive perceptions of relationships with adults, including parents and teachers (Chan et al., in press), and peers (Karcher 2008), and to a general sense of greater school connectedness (Portwood et al. 2005). SBM also has been found to contribute to the academic well-being of mentored students, providing positive outcomes, such as lower rates of disciplinary referrals (Converse and Lingnugaris/Kraft 2009), improved self-perception of learning competence and better school grades (Herrera et al. 2011). However, the size of SBM effects on the mentees' well-being tends to be small (Dubois et al. 2011). In this context of mixed results, some studies have determined the cornerstone factors that influence the general effectiveness of school mentoring. The mentor's prior experience in caring or educational roles (Dubois et al. 2002) and the mentee's accumulation of individual risk (Schwartz et al. 2011) are among the most relevant ones.

\subsection{SBM: Present Limitations}

SBM is increasingly provided by schools. The outstanding dissemination of SBM programs has resulted in a considerable amount of well-publicized research efforts to test its effectiveness. However, some limitations in this research field are noteworthy. First, there is the possibility of transforming SBM into an automatic solution for at-risk students, despite the considerable variations in the programs' characteristics and implementation forms (Dubois et al. 2011). Second, previous findings on good SBM practices do not appear to have been properly integrated into the organization of SBM programs. This problem is particularly notable in the selection of mentors. Mentors are typically volunteers from the community who, to a certain extent, appear to influence negatively the outcomes of the interventions (Dubois et al. 2002). Occasionally, the volunteers do not have sufficient relevant experience in educational or caring roles to mentor. In addition, the absence of a proper match between the mentor and the mentee and some difficulties determining a suitable schedule for mentoring activities are practical problems that frequently arise from choosing mentors that are not members of the school's staff (Karcher 2008). Finally, a substantial number of studies of the effectiveness of SBM is focused on its effects on well-being without providing an obvious theoretical framework for the interpretation of the results (Larson 2006; Russell 2007). Thus, new research contributions are necessary in order to understand SBM effectiveness, not only to promote a proper dissemination of mentoring practices in schools, but also to ensure that the outcomes are interpreted according to suitable theoretical approaches.

\subsection{SBM and Self-Determination Theory}

SBM research has been extensively inspired by two leading human development theories. Some studies have relied on the attachment theory premise that mentoring provides 
children and adolescents who have experienced adversities in their lives an opportunity to readjust their internal working models and compensate for losses in previous relationships with adults (Rutter 2006). Other studies integrate the assumption of resilience theory that mentoring is an external developmental resource that may buffer the pervasive effects of risk factors in the lives of vulnerable children and youth (Edwards et al. 2007). Despite the fruitful conclusions generated by these perspectives, recommendations have been made to dedicate further attention to the discussion of mentoring outcomes from other theoretical perspectives (Larson 2006). In that respect, Self-Determination Theory (SDT) appears to be an appropriate and promising framework. SDT is a theory of personal development that assumes that each individual has an internal organizational motivation directed toward personal development and the resolution of internal inconsistencies. Personal development will vary according to the level of satisfaction of the three Basic Psychological Needs (BPN): competence, relatedness and autonomy (Deci and Ryan 2000). Competence is described as a feeling of effectiveness as a consequence of successful personal experiences of challenge and mastery. Relatedness involves a personal orientation toward establishing strong, stable interpersonal bonds that promote a sense of being understood and accepted by others. Finally, autonomy refers to self-initiation, volition and a willing endorsement of one's own behavior (Vanteenkiste et al. 2009).

Some authors have maintained that although these BPN are distinct, it is reasonable to study the satisfaction of these needs as a whole in naturalistic contexts (Bartholomew et al. 2011). In accordance with this view, higher levels of satisfaction of BPN have been associated with some indicators of students' well-being, such as increased psychological well-being (Levesque et al. 2004), increased social support from peers and improved school adjustment (Milyavskaya et al. 2009).

\subsection{Current Study}

\subsubsection{Purpose and Premises}

The aim of this study is to investigate the effect of satisfaction of BPN on the well-being of the mentored students in a SBM program called Metodologia TUTAL. To accomplish that goal, a two-wave experimental study design was implemented. The first assessment (time point 1) was made 2 months after the program began. The second assessment (time point 2) was made 6 months later, after the SBM program was completed. The assessment of perceived satisfaction of BPN (increased or unchanged/lowered satisfaction) in mentored and non-mentored students, as well as subgroups of mentored and non-mentored students, was measured across the assessment time periods. The comparisons relied on three central premises. First, the conditions under which social support was delivered in SBM would be best described by satisfaction of BPN as defined by SDT. Second, the well-being of mentored students would be more accurately studied according to three complementary dimensions of well-being: personal well-being (in terms of physical well-being, psychological well-being and hope), social well-being (through parent relations and autonomy, and social support and peers) and academic well-being (in terms of school environment and perceived competence in learning). Third, key moderators of SBM programs should be duly considered because the mentors, in this program, were experienced educators; they were simultaneously teachers of the mentees; and the mentees were targeted as students atrisk (Dubois et al. 2002). The students' individual risk was considered for selection purposes as described in Sect. 2.1. 


\subsubsection{Hypotheses}

Six hypotheses were tested. It was expected that the evolution of the results between time points 1 and 2, in physical well-being, psychological well-being, hope, parent relations and autonomy support, social support and peers, perceptions of school environment and perceived competence in learning would be significantly related to the interaction between SBM and the satisfaction of BPN (hypothesis 1). In addition, mentored students who perceived an increase in the satisfaction of the BPN between the assessed time points would exhibit significantly better outcomes in the selected dependent variables than would the equivalent non-mentored students (hypothesis 2) and both the non-mentored students (hypothesis 3) and the remaining mentees that perceived less or unchanged satisfaction of BPN (hypothesis 4). Conversely, mentored students who considered themselves less or similarly supported in their BPN would not exhibit significant better results in the considered dependent variables when compared to the non-mentored students, whether these had perceived less or similar satisfaction between the assessments (hypothesis 5). Finally, the non-mentored students who perceived increased support of their BPN from time point 1 to time point 2 would present significantly better outcomes in the selected dependent variables compared to those who felt less or similarly supported, for that period of time, despite the mentoring (hypothesis 6).

\section{Methods}

\subsection{Participants}

The participants in this study were students enrolled in six schools of the Portuguese public educational system that implemented the Metodologia TUTAL during the 2010/2011 school year. A total of 551 potential participants were integrated into 27 classes assigned to the study by their respective school boards. The classes were randomly assigned to either the mentored or the non-mentored group. Most of the students met at least one of the four inclusion criteria: recommendation for supplementary classes, a record of prior retentions, school attendance problems, or a record of disciplinary referrals. These criteria were chosen as both academic and behavioral risk factors must be regarded in risk assessment (Schwartz et al. 2011). From the 551 potential participants, 53 did not meet at least one of the criteria and were excluded from the study. A total of 181 students either did not complete the questionnaire at time point 1 or 2 or did not receive authorization from their legal representatives to participate in the research. The final sample included 317 students, representing a participation rate of $63.7 \%$.

Of the 317 participants, 181 were female $(57.1 \%)$. At the beginning of the school year, the students' ages ranged from 9 to 16 years $(M=12.40, \mathrm{SD}=1.81)$. A total of 183 students $(57.7 \%)$ attended classes at the third level of Portuguese basic education (7th and 8th grades). The mentored group included 157 students (49.5\%), of whom $90(57.3 \%)$ were female. The ages in this group ranged from 9 to 16 years $(M=12.75, \mathrm{SD}=1.75)$. In addition, 93 of the mentees $(59.2 \%)$ attended classes at the third level of basic education. Regarding the risk factors considered inclusive criteria, 131 of the mentored students had been referred to supplementary classes, 126 had been retained at least once, 115 had a history of absenteeism, and 41 had a record of disciplinary referrals. The non-mentored group comprised 160 students $(50.5 \%)$, of whom $91(56.9 \%)$ were female. The ages in this group ranged from 9 to 16 years $(M=12.06, \mathrm{SD}=1.81)$. Furthermore, $90(56.3 \%)$ 
attended classes at the third level of basic education. With respect to the risk factors, 89 of the non-mentored students had been referred to supplementary classes, 85 had been retained at least once, 116 had a record of absenteeism problems, and 42 had a record of disciplinary referrals.

The mentored students were significantly older than the non-mentored students, $t(1$, $316)=3.130, p=.002$ and had a greater chance of being previously retained, $\chi^{2}(1$, 316) $=26.205, p=.000$.

\subsection{Metodologia TUTAL}

Metodologia TUTAL is a SBM program developed in Portugal by a consortium of public and private organizations under a grant from the European Social Fund (EQUAL Communitarian Initiative). The program defines SBM as a method of support and orientation provided by a more experienced individual (the mentor) to a child or adolescent (the mentee) during, at least, one school year (Alarcão and Simões 2008). The selection of mentors and mentees integrates recommendations of previous studies. An uncommon feature of this program is that the mentors are also the teachers of the mentees. Preferably, the mentors are members of the school's permanent staff and have experience as informal mentors in educational settings or the community. The mentees are students targeted by school boards because of low rates of school attendance, disciplinary problems and/or underachievement.

The mentors are enrolled in a 16-h training program prior to the beginning of the official school year. Ongoing supervision of the program includes monthly meetings and informal communication by phone and e-mail with a designated coordinator (Alarcão and Simões 2008). The mentoring activities occur in two formats. Weekly one-on-one mentoring meetings, which do not overlap with the mentees' classes, are scheduled. These sessions focus on the following: (a) supporting the mentee's competence needs by offering help with academic-related tasks, such as assisting with homework, teaching study methods and preparing for tests; (b) supporting the mentees' relatedness needs by discussing personal matters, such as stressful or positive relationships with peers and teachers and family issues emphasizing relational interest, empathy, authenticity and trust; (c) supporting the mentees' autonomy needs through the discussion or role-modeling of self-regulation strategies related to school attendance or classroom behavior or providing information related to important decisions, such as choosing future training or learning programs. One-on-one mentoring also includes informal activities, such as contacts outside the classroom or office encouraged by the mentor. Mentors are taught the importance of delivering balanced support to the different BPN. However, they are intentionally given the opportunity to regulate the dosage of the support given to these different needs and to choose the activities developed with the mentees during SBM sessions. Group mentoring is also organized as compulsory, 90-min weekly meetings. The group mentoring is focused on the orientation of the mentees' schoolwork, the promotion of their social integration and the discussion of themes that are relevant to each group. The combination of individual and group mentoring activities is intended to increase the integration of mentoring with the expected social behavior and learning performance of the mentees in the classroom (Wilson and Lipsey 2007).

\subsection{Measures}

There is no standard method to assess well-being (Pollard and Lee 2003). For example, the association between social support and well-being may be studied using different measures 
and assessment approaches, such as the perceived enacted support in a particular relationship or social network size and density (Chu et al. 2010). In the present study, the hypotheses were tested by the enacted social support experienced by the participants in their SBM relationships. In the case of children and adolescents, enacted support has been described as the most effective technique to evaluate possible associations between different forms of social support and well-being (Chu et al. 2010). This option has influenced the selection of the independent and dependent measures.

\subsubsection{Independent Measure}

2.3.1.1 Basic Need Satisfaction in Relationships Scale (BNSRS) The Portuguese version of the BNSRS (Simões and Alarcão 2013a) includes 9 items, which are rated on a 5-point Likert scale that ranges from 1 (never) to 5 (always). The possible scores range from 5 to 25 points, with higher scores indicating greater satisfaction of BPN in a particular relationship. The items are grouped into 3 factors that correspond to each of the BPN proposed by SDT. Each factor includes 3 items: 2 items are affirmative and the third item is reversed, with higher levels corresponding to low levels of support provided for that particular basic need. The BNSRS allows an evaluation of the satisfaction of BPN in any targeted relationship. In this study, the BNSRS was used to evaluate the mentored and non-mentored students' appraisals of the level of BPN support offered by their school mentors or class directors. The option of rating relationships with class directors was provided to the nonmentored students because this was their most relevant relationship with a teacher. The levels of internal consistency of the BNSRS in this study were adequate at both the pre-test $(\alpha=.79)$ and post-test $(\alpha=.87)$.

2.3.1.2 KIDSCREEN-27 The KIDSCREEN-27 assesses quality of life in children and adolescents between 8 and 18 years of age (Ravens-Sieberer et al. 2007). The 27 items included in this instrument are organized into 5 dimensions. Physical Well-Being (5 items) explores the level of the child's/adolescent's physical activity, energy and fitness. Psychological Well-Being (7 items) includes measures of positive emotions, satisfaction with life and emotional balance. Parent Relations \& Autonomy (7 items) examines relationships with parents, the atmosphere at home, feelings relative to age-appropriate freedom, and the degree of satisfaction with financial resources. Social Support \& Peers (4 items) examines the nature of the respondents' relationships with other children/adolescents. Finally, School Environment (4 items) explores the child's/adolescent's perceptions of his/her cognitive capacity, learning and concentration, and feelings regarding school (Ravens-Sieberer et al. 2007). For each dimension, the respondents describe their perceptions during the previous week. Depending on their nature, the items are rated on a 5-point Likert scale of intensity (ranging from $1=$ nothing to $5=$ extremely) or frequency (ranging from $1=$ never to $5=$ always). The whole-scale scores range from 5 to 135 points, with higher scores denoting a more positive perception of the quality of life. The level of internal consistency of the KIDSCREEN-27 in this study was adequate for both the pre-test $(\alpha=.88)$ and the post-test $(\alpha=.89)$.

2.3.1.3 Perceived Competence in Learning Scale (PCLS) The Portuguese version of the PCLS is an adaptation of the original English version (Simões and Alarcão 2011) that assesses the subjective level of competence in learning within a given context. The PCLS includes 4 items that are rated on a 5-point Likert scale from 1 (never) to 5 (always), with 
whole-scale scores ranging from 5 to 20 points. Higher scores indicate a more positive perception of competence in learning. The level of internal consistency of the PCLS in this study was adequate for both the pre-test $(\alpha=.78)$ and the post-test $(\alpha=.81)$.

2.3.1.4 Children's Hope Scale (CHS) The CHS is composed of 6 affirmative items that measure goal-related hopeful thinking in children and adolescents from 8 to 16 years of age. The 6 items included in this scale are rated on a 6-point Likert scale from 1 (none of the time) to 6 (all of the time). The CHS is divided into 2 factors, Pathways and Initiative; in this study, the scale was used only as a general measure of hope. The Portuguese version of this measure that was used in this study (Marques et al. 2009). In the present work, the levels of internal consistency of this scale were adequate for both the pre-test $(\alpha=.74)$ and the post-test $(\alpha=.80)$.

\subsection{Procedures}

Prior to data collection, written consent forms explaining the objectives, procedures and confidentiality of this research were sent by the school boards to the legal representatives of the participants. Verbal consent was obtained from the students at time points 1 and 2. The surveys were administered in a group format, with the groups ranging from 4 to 34 participants. The surveys at time point 1 were collected in November 2010, 2 months after the beginning of the school year, whereas the surveys at time point 2 were collected in May and June 2011. The surveys were completed during a Citizenship class when no teachers were present. Figure 1 depicts the entire assessment plan, including the independent and the dependent variables, the measures and instruments used to assess each of the variables and the assessment points.

\subsection{Data Analysis}

Exploratory, descriptive and inferential analyses were conducted using the Statistical Package for Social Sciences (SPSS) v. 19.0. An exploratory analysis was performed to

Independent measures $\quad$ Dependent measures

T1

Basic Psychological Needs (BPN)

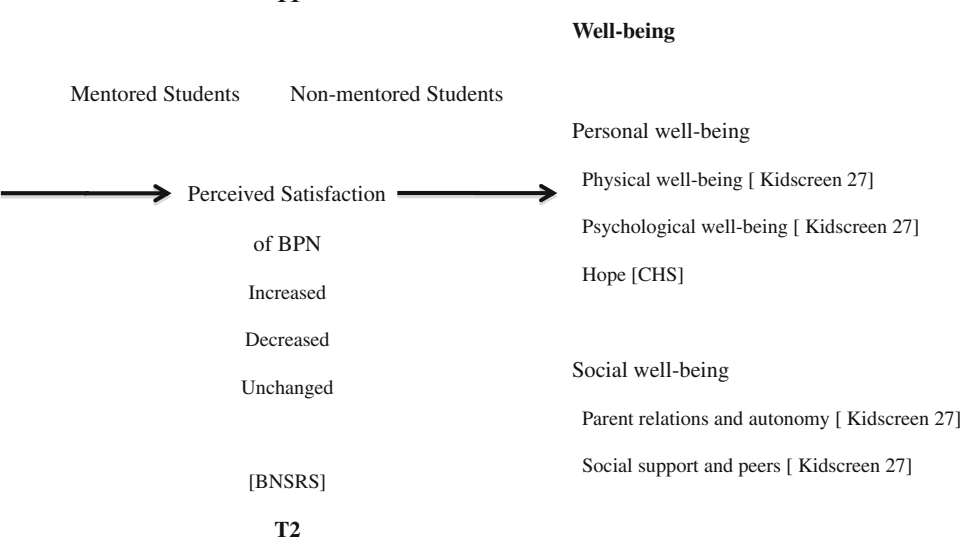

Fig. 1 Assessment plan—independent measure, dependent measures, instruments and assessment points 
Table 1 Mentored students (MS) non-mentored students (NMS) descriptive statistics for the independent and the dependent measures

\begin{tabular}{|c|c|c|c|c|}
\hline \multirow[t]{2}{*}{ Measures } & \multicolumn{2}{|l|}{ Time point 1} & \multicolumn{2}{|l|}{ Time point 2} \\
\hline & $\begin{array}{l}\text { MS }(n=157) \\
\mathrm{M}(\mathrm{SD})\end{array}$ & $\begin{array}{l}\text { NMS }(n=160) \\
\text { M (SD) }\end{array}$ & $\begin{array}{l}\mathrm{MS}(n=157) \\
\mathrm{M}(\mathrm{SD})\end{array}$ & $\begin{array}{l}\text { NMS }(n=160) \\
\text { M (SD) }\end{array}$ \\
\hline Satisfaction of BPN & $33.96(6.64)$ & $34.49(7.18)$ & $34.40(6.99)$ & $32.95(8.13)$ \\
\hline Physical well-being & $18.39(3.76)$ & $19.32(3.45)$ & $19.25(3.36)$ & $18.94(3.56)$ \\
\hline Psychological well-being & $27.74(4.81)$ & $28.54(4.45)$ & $28.52(4.87)$ & $27.93(5.31)$ \\
\hline Autonomy and parental relations & $28.36(5.26)$ & $29.16(4.87)$ & $28.96(4.89)$ & $28.81(5.14)$ \\
\hline Social support and peers & $16.71(3.01)$ & $17.01(2.81)$ & $17.07(2.81)$ & $16.88(2.74)$ \\
\hline School environment & $14.63(3.13)$ & $14.85(2.79)$ & $15.10(2.84)$ & $14.36(2.53)$ \\
\hline Hope & $26.11(5.75)$ & $26.96(5.37)$ & $26.88(4.71)$ & $26.31(5.46)$ \\
\hline Perceived competence in learning & $18.46(4.44)$ & $18.51(3.78)$ & $18.63(3.64)$ & $18.38(3.61)$ \\
\hline
\end{tabular}

$M S$ mentored students, NMS non-mentored students

verify the patterns of missing data. The missing data were random and limited $(<2.2 \%)$ and were, therefore, handled with a simple group mean substitution.

The hypotheses were tested through multivariate analyses of covariance (MANCOVA), which were deemed to be the most appropriate statistical approach because it reduced the risk of inflation associated with performing individual analyses of variance. The assumptions underlying MANCOVA were tested. In general, there were moderate correlations between the dependent variables assessed at time points 1 and 2. Normality was verified using the Kolmogorov-Smirnov test with a Lilliefors correction, and the homogeneity of variances was examined using Levene's test.

An initial MANCOVA was performed to test hypothesis 1. All the dependent measures assessed at time points 1 and 2 were included as within-subjects variables. The type of group (mentored or non-mentored) and the satisfaction of the participants' BPN were calculated as between-subjects variables to study the main effects across time. Age and record of prior retentions were considered as covariates. To assess hypotheses 2 through 6 , all the dependent measures were reexamined as within-subjects variables using MANCOVA. A new factor was introduced to calculate the group differences between time points 1 and 2 in terms of the levels of support of BPN. This factor was divided into four levels: mentored students with an increased satisfaction of BPN $(n=88)$; mentored students with a lower or unchanged satisfaction of BPN $(n=69)$; non-mentored students with an increased satisfaction of BPN $(n=61)$; and non-mentored students with a lower or unchanged satisfaction of BPN $(n=99)$. This variable was included in the model as the between-subjects factor. Age and prior retentions were again considered as covariates. This analysis included post hoc tests for multiple comparisons of the observed means using Fisher's Least Significant Difference test. The effect sizes $\left(\eta p^{2}\right)$ were calculated for both MANCOVAs. The level of significance for the statistical tests was set at $p<.05$ (Table 1 ).

\section{Results}

Here, the results of the different comparisons between the mentored and non-mentored students are presented for each of the previously stated hypotheses: 
Table 2 MANCOVA - the results of the different dependent measures with the type of group (mentored or non-mentored), the satisfaction of BPN and the interaction of the type of group with the satisfaction of BPN as between-subjects factors and age and prior retentions as covariates

\begin{tabular}{lccc}
\hline Dependent measures & $\begin{array}{c}\text { Type of group } \\
\text { (mentored or non- } \\
\text { mentored students) }\end{array}$ & Satisfaction of BPN & $\begin{array}{c}\text { Type of group } \times \\
\text { satisfaction of BPN }\end{array}$ \\
\hline Physical well-being & $F(1,316)=1.92$, & $F(1,316)=.98$, & $F(1,316)=.79$, \\
Psychological well-being & $F p^{2}=.01$ & $\eta p^{2}=.15$ & $\eta p^{2}=.08$ \\
& $\eta p^{2}=.01$ & $F(1,316)=1.31$, & $F(1,316)=1.17$, \\
Autonomy and parental & $F(1,316)=1.49$, & $F(1,316)=.92$, & $\eta p^{2}=.12$ \\
relations & $\eta p^{2}=.01$ & $\eta p^{2}=.15$ & $F(1,316)=.91$, \\
Social support and peers & $F(1,316)=.10$, & $F(1,316)=.80$, & $\eta p^{2}=.10$ \\
School environment & $\eta p^{2}=.01$ & $\eta p^{2}=.13$ & $F(1,316)=.78$, \\
& $F(1,316)=.03$, & $F(1,316)=1.843$, & $\eta p^{2}=.08$ \\
Perceived competence in & $F(1,316)=.26$, & $F(1,316)=1.58$, & $F(1,316)=1.37$, \\
learning & $\eta p^{2}=.001$ & $\eta p^{2}=.2 p^{2}$ & $F(1,316)=1.07$, \\
Hope & $F(1,316)=.17$, & $F(1,316)=1.48$, & $\eta p^{2}=.11$ \\
& $\eta p^{2}=.000$ & $\eta p^{2}=.22^{2}$ & $F(1,316)=1.36$, \\
& & & $\eta p^{2}=.14$
\end{tabular}

$* p<.05, * * p<.01$

Table 3 MANCOVA: differences between the mentored students (MS) and non-mentored students (NMS) with increased, decreased or unchanged satisfaction of BPN as between-subjects factors and age and prior retentions as covariates

\begin{tabular}{ll}
\hline Dependent measures & $\begin{array}{l}\text { MS or NMS } \times \text { different levels } \\
\text { of satisfaction of BPN }\end{array}$ \\
\hline Physical well-being & $F(3,314)=2.45, \eta p^{2}=.02$ \\
Psychological well-being & $F(3,314)=8.53, \eta p^{2}=.08^{* *}$ \\
Autonomy and parental relations & $F(3,314)=2.42, \eta p^{2}=.02$ \\
Social support and peers & $F(3,314)=4.88, \eta p^{2}=.05^{*}$ \\
School environment & $F(3,314)=10.67, \eta p^{2}=.09^{* *}$ \\
Perceived competence in learning & $F(3,314)=16.60, \eta p^{2}=.14^{* *}$ \\
Hope & $F(3,314)=9.98, \eta p^{2}=.09^{* *}$
\end{tabular}

$* p<.01, * * p<.001$

Hypothesis 1 Significant MANCOVA effects were obtained for the type of group, Wilks' lambda $F(8,195)=2.59, p=.01$, and for the satisfaction of BPN, Wilks' lambda $F(544,1,570)=1.15, p=.02$, but not for the interaction between these two factors Wilks' lambda $F(344,1,564)=.96, p=.70$ (Table 2). The results in Table 3 indicate that the variations in the results for three of the dependent variables (school environment, perceived competence in learning and hope) between time points 1 and 2 were significantly correlated with the perceived satisfaction of BPN. Notably, this relationship approached statistical significance for two of the dependent measures, psychological well-being, $F(3$, $314)=1.304, p=.08$, and perceived decision in learning $F(3,314)=1.304, p=.07$. In addition, the interaction between mentoring and the satisfaction of BPN was not significantly associated with any of the dependent measures. Overall, the evidence does not support hypothesis 1 . 
Hypothesis 2 A significant MANCOVA effect was observed for the comparison of mentored and non-mentored students regarding the evolution of their perceived satisfaction of BPN across the two assessments, Wilks' lambda $F(27,789)=2.28, p=.000$. The data presented in column 1 of Table 4 reveal that the mentees who felt increased support for their BPN exhibited higher ratings for physical well-being, school environment and perceived competence in learning than did the non-mentored students who also experienced an increased of the satisfaction of BPN. In the case of school environment perceptions, the difference between the two groups was significant $(p<.05)$. Conversely, the non-mentored students who experienced increased support for their needs had more positive, but non-significant outcomes for physical well-being $(p=.20)$, autonomy and parent relation $(p=.73)$, social support and peers $(p=.06)$ and hope $(p=.42)$ than did the equivalent mentees. However, these differences were not statistically significant. In summary, hypothesis 2 was not supported by the data, with the exception of the school environment evaluations.

Hypothesis 3 A comparison of the mean numbers of mentees who perceived increased support of BPN and non-mentored students who perceived lower or unchanged support for their BPN revealed significant differences in five of the dependent variables $(p<.05)$. These results are shown in column 2 of Table 4 . No differences were observed for physical well-being $(p=.20)$ and autonomy and parent relations $(p=.73)$. This empirical evidence considerably supported hypothesis 3 .

Hypothesis 4 The results in column 3 of Table 4 indicate that the rates of all the dependent variables for the mentees who perceived increased support for their BPN were more positive than those of the mentees in the reverse condition. There were significant mean differences between the members of the experimental group in these two conditions for all of the dependent variables $(p<.05)$, with the exception of social support and peers $(p=.56)$. Thus, hypothesis 4 was strongly supported by the empirical evidence.

Hypothesis 5 Hypothesis 5 was fully supported by the results of multiple comparisons of the rates of the mentees with less or unchanged support for their BPN between time points 1 and 2 and the non-mentored students in the identical condition. No significant differences, in any of the dependent variables, were observed between these subgroups. These results are shown in the fourth column of Table 4.

Hypothesis 6 Finally, the multiple comparisons showed in column 5 depict significant differences $(p<.05)$ between the rates of non-mentored students who experienced lower or unchanged support of BPN and non-mentored students in the opposite condition, with the exceptions of physical well-being $(p=.52)$. The non-mentored students with increased support for their BPN also rated the different dependent variables more positively compared with the mentees who felt less supported. However, column 6 shows that significant differences were detected between the groups in only three dimensions: physical wellbeing, psychological well-being and hope $(p<.05)$. Therefore, these mixed findings partially support hypothesis 6 .

\section{Discussion}

\subsection{Mentoring Focus, Activities and Relational Style}

The foremost conclusion of this study is that SBM associated with increased satisfaction of BPN was the most effective condition for promoting improvements in of the 


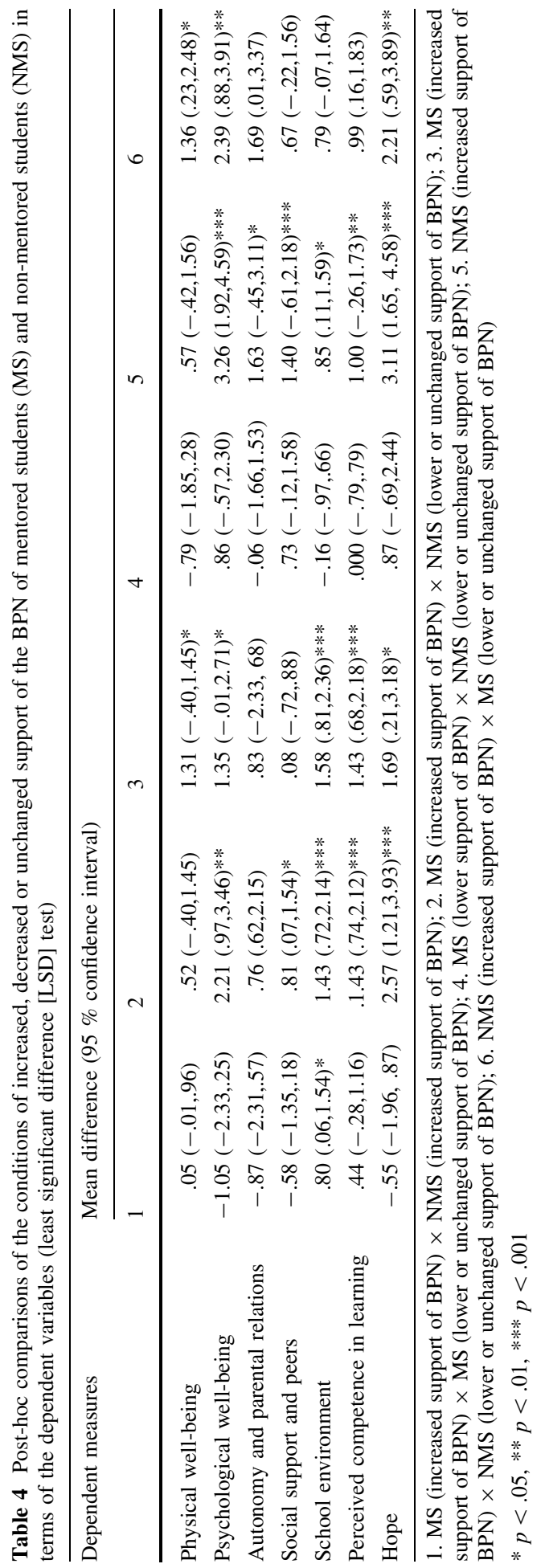


academic-related well-being (perceptions of the school environment and perceived competence in learning). It is likely that SBM was effective in maintaining academic well-being in Metodologia TUTAL due to a complex combination of factors that affected the mentoring focus, activities and relational style of the mentor (Karcher and Nakkula 2010). Teachers have been identified as an important source of social support for students (Chu et al. 2010). The social support delivered by teachers has been associated, in general, with academic well-being indicators such as better school engagement and the improvement of school grades (Roorda et al. 2011). SBM has also proven to be effective in promoting the students' academic well-being. Providing a school mentor to more vulnerable students has been linked with lower rates of disciplinary referrals (Converse and Lingnugaris/Kraft 2009), improved perceptions of competence in learning and better school grades (Herrera et al. 2011). In addition, the academic-related effectiveness of SBM is positively moderated if mentors are experienced educators, as is the case in Metodologia TUTAL (Dubois et al. 2002). Thus, the mentors, because they were also teachers, may have seen mentoring as an opportunity to improve their mentees' perceptions of school and learning. This focus may have led to the frequent pursuit of academic activities, such as assisting with homework, studying together or preparing tests, held in one-on-one and group mentoring sessions. This interpretation is consistent with the results of exploratory studies on the same program, which depict SBM sessions as dominated by learning issues (Simões and Alarcão 2013b), as well as with similar findings presented in the literature (e.g. Herrera et al. 2011). As a consequence, it is likely that this SBM main focus led to a relational style largely orientated toward deficit reduction (Karcher and Nakkula 2010; Lavigne et al. 2011). Based on the program's activities and the mentored students' characteristics, the mentors may have thought that SBM was mostly a chance to alter an unsuccessful school trajectory, thus limiting the exploration of alternative goals.

It is reasonable to assume that the mentees had diverse responses to this approach. Some mentees might have recognized that SBM contained the structure that was lacking in their previous school relationships or in their lives in general, making them more prone to comply with school demands. Other mentees may have been particularly sensitive to the approval of others or were motivated to perform well in school despite their past failures (Schüler et al. 2009). Conversely, some mentees may have felt conditionally accepted or may not have recognized mentoring as distinct from teaching, thus increasing their reluctance to be mentored. The latter situation likely occurred with those mentored students who accumulated lower or greater individual risk, because such mentees have been shown to benefit less from being mentored due to prior or current (un)fulfilling relationships (Schwartz et al. 2011).

As a consequence of the mentoring focus and the mentored students' characteristics, the mutual expectations and actions of the mentors and mentees likely influenced the satisfaction of the mentees' BPN (Deci and Ryan 2000). The mentees who felt comfortable with a competence-focused approach aimed at reducing their deficits may have experienced or received higher levels of needs satisfaction throughout the school year, whereas the reverse likely occurred for those mentees who did not appreciate this relationship style. Ultimately, this competence reduction-deficit approach may have facilitated the fulfillment of academic well-being. Nevertheless, this perspective likely prevented the satisfaction of the mentees' relatedness and autonomy needs, which has been associated with positive changes in personal and social well-being (Karcher and Nakkula 2010; Lavigne et al. 2011). 


\section{2 (Un)balanced Satisfaction of BPN and Time}

The second finding that emerged from this study is that the interaction between being mentored and having BPN satisfied was not significantly associated with a positive evolution of the results in any of the dependent variables, between time points 1 and 2. Possibly, a more balanced support for the mentees' BPN was necessary to produce systematic effects on the overall evolution of well-being from time point 1-2 in the context of SBM. Relationships that offer a combination of structure (Karcher and Nakkula 2010) while nurturing the senses of belonging (Lavigne et al. 2011) and choicefulness (Vanteenkiste et al. 2009) appear to be associated with more positive perceptions of well-being. However, there is no universal agreement on the importance of fulfilling all BPN. For instance, Vanteenkiste et al. (2009) maintain that the satisfaction of these needs depends upon individual differences. According to this view, these differences may be related to the individual's developmental stage or prior experiences with the satisfaction of BPN in personal relationships (Lavigne et al. 2011; Schüler et al. 2009). Other researchers disagree, stressing that a balanced support of BPN is vital both within relationships (Deci and Ryan 2000) and across different relationships and contexts (Milyavskaya et al. 2009). In addition, other authors emphasize that the balanced support of needs in a new context will increase the probability of a person engaging with the challenges within that context and experiencing a greater sense of control over his or her behavior (Ciani et al. 2011). In our opinion, the developmental stages of the mentored students and their stories of failures and losses are crucial factors that require for a more thoughtful consideration of all BPN in SBM, in order to improved these students' well-being (Bergin and Bergin 2009; Véroneau et al. 2004).

A third and final finding delivered by this study was that SBM based on increased support of BPN was not significantly more effective in improving the personal well-being (physical and psychological well-being, as well as hope) or the social well-being (parent relations and autonomy and social support and peers) of the mentees between both assessments compared with the overall levels of support of BPN. A possible unbalanced satisfaction of BPN may also underlie this finding. However, the duration of the program was limited as well: it lasted for 9 months, and 6 months passed between the first and second evaluations. Although SBM relationships that last longer than 6 months have been reported to be associated with more positive outcomes (Grossman et al. 2012), direct comparisons between different programs are limited. Moreover, changes in perceptions of personal and social well-being occur over time and amidst improvements and setbacks; thus, a single school year was likely too brief to promote dramatic and sustained changes in this area (Herrera et al. 2011).

Additional time could ensure that other needs were properly addressed. For example, a sense of relatedness depends on trust (Bergin and Bergin 2009) and emotional reliance (Ryan et al. 2005). Because of their history of school misconduct, it is highly probable that most of the mentees required that more time was provided to trust their mentors sufficiently for self-disclosure. Similarly, some exploratory findings regarding the Metodologia TUTAL showed that the mentored students' relatedness needs were more often addressed when the mentoring relationship lasted for 2 years (Simões and Alarcão 2013b). Therefore, enduring relationships may be crucial in facilitating more obvious effects of SBM on the mentees' personal and social well-being.

\subsection{Implications, Recommendations and Limitations}

The present findings have research and practical implications. Some of these implications stem from the limitations of this work, justifying further recommendations. From a 
research perspective, it is important to approach the satisfaction of BPN in SBM from a variety of angles. It is critical to study how the fulfillment of BPN can be (un)balanced and how this fulfillment is qualitatively provided (Vanteenkiste et al. 2009). For example, the decision to provide support using a controlling versus an autonomous relational style may have significant implications. Future research on this particular SBM program should also examine the moderating effect of the dosage of mentoring or emotional reliance (Ryan et al. 2005) on the outcome of well-being. These dimensions were not systematically measured in this study and represent a noteworthy limitation. Moreover, although the assessment of enacted support is the most reliable form to evaluate the association between social support and well-being (Chu et al. 2010), future studies on this topic should be based on different forms of assessment. The simultaneous use of deficit indicators (e.g. depression) and positive indicators of well-being would be an appropriate approach to the measurement issues. The combination of students' measures as the ones used in this study, with classroom (e.g. organization or size) and school measures (e.g. school culture), is also highly recommendable to get a more comprehensive picture of SBM effectiveness (Pollard and Lee 2003). Furthermore, while the selection of dependent measures in this study complied with the definitions of well-being as a multidimensional concept (Diener 2009; Huta and Ryan 2010), it is possible that they may have influenced the findings to a certain extent. A noteworthy example is the assessments of the participants' parent relationships which were made in association with autonomy issues. The influence of the social support provided by SBM in the mentees' parental relationships may have been limited when the scope of the analysis relies on a continuum of control versus autonomy, which is usually a source of conflict between children and parents, especially during adolescence (Chu et al. 2010). Finally, it is important to expand on these findings by conducting longitudinal comparisons between this type of SBM and other programs delivered by volunteers or teachers. Therefore, the generalization potential of the results is another limitation of the present work, although this is a significant drawback of SBM programs in general because of the variability in program designs (Dubois et al. 2011).

From a practical point of view, the combining of the roles of mentor and teacher represents an integration of previous findings that adults with greater experience in educational roles may be in a better position to mentor (Dubois et al. 2002). However, there are predictable drawbacks associated with this assumption that must be addressed. The most important consideration is to ensure a more balanced satisfaction of BPN in SBM delivered by the Metodologia TUTAL. The results indicate that competence needs should continue to be nurtured; however, the support of relatedness and autonomy needs must constitute the core premise of training and supervision activities to enable a more positive evolution of the mentees' overall well-being (Karcher and Nakkula 2010). More attention to relatedness needs may enhance the emotional reliance of the mentored students on their mentors, thus facilitating improvements in personal and social well-being. In addition, sustained support for autonomy needs may lead to greater and more enduring social and emotional improvements in the lives of the mentees (Ciani et al. 2011). Finally, SBM delivered by teachers may benefit from extended time frames (more than one school year), which can be facilitated by the typical presence of the mentors on the permanent teaching staff of the school.

\section{Conclusions}

A single question motivated this research: is social support, through the satisfaction of BPN, essential for improving the well-being of the mentored students in SBM? The need 
for a better understanding of this topic was clear in a research context in which SBM is often delivered without obvious theoretical grounds. The results suggest that supporting BPN is a promising approach to promote the mentored students' academic well-being in the short-term. However, the relational complexity of mentoring vulnerable children and youth, as well as the provision of SBM by teachers in this program, suggest that a balanced support of the competence, relatedness and autonomy needs of the mentees may also be critical for promoting their personal and social well-being. If this concern is properly addressed and if the mentoring relationships persist for at least one school year, this SDTbased SBM approach may be adequate to expand knowledge on how mentoring may be effectively delivered in schools as well as to establish practical implications for the program design and the mentors' training and supervision.

Acknowledgments The authors would like to thank the participants. They would also like to thank Marco Pereira for his comments on data analyses procedures and the reviewers for their valuable contributions. This work was supported by a grant of the Foundation for Science and Technology (SRFH/BD/60823/2009).

\section{References}

Alarcão, M., \& Simões, F. (2008). TUTAL—metodologia de intervenção com alunos e alunas promovida por professores tutores. [TUTAL-methodology of intervention with students promoted by mentors.] Oliveira de Azeméis: Papel de Carta.

Bartholomew, K. J., Ntoumanis, N., Ryan, R. M., \& ThØgersen-Ntoumani, C. (2011). Psychological need thwarting in the sport context: Assessing the darker side. Journal of Sport and Exercise Psychology, 33(1), 75-102.

Bergin, C., \& Bergin, D. (2009). Attachment in the classroom. Educational Psychology Review, 21(2), $141-170$.

Chan, C. S., Rhodes, J. E., Howard, W. J., Lowe, S. R., Schwartz, S. E. O., \& Herrera, C. (2013). Pathways of influence in school-based mentoring: the mediating role of parent and teacher relationships. Journal of School Psychology, 51(1), 129-142.

Chu, P. S., Saucier, D. A., \& Hafner, E. (2010). Meta-analysis of the relationships between social support and well-being in children and adolescents. Journal of Social and Clinical Psychology, 29(6), 624-645.

Ciani, K. D., Sheldon, K. M., Hilpert, J. C., \& Easter, M. A. (2011). Antecedents and trajectories of achievement goals: A self-determination theory perspective. British Journal of Educational Psychology, 81(2), 223-243.

Cohen, S. (2004). Social relationships and heath. American Psychologist, 59(8), 676-684.

Converse, N., \& Lingnugaris/Kraft, B. (2009). Evaluation of a SBM program for at-risk middle school youth. Remedial and Special Education, 30(1), 33-46.

Deci, E. L., \& Ryan, R. M. (2000). The "what" and "why" of goal pursuits: Human needs and the selfdetermination of behavior. Psychological Inquiry, 11(4), 227-268.

Diener, E. (1984). Subjective well-being. Psychological Bulletin, 95, 542-575.

Diener, E. (2009). The science of well-being: The collected works of Ed Diener. Social Indicators Research Series, 37, 11-58.

DuBois, D. L., Holloway, B. E., Valentine, J. C., \& Cooper, H. (2002). Effectiveness of mentoring programs for youth: A meta-analytic review. American Journal of Community Psychology, 30(2), 157-197.

DuBois, D. L., Portillo, N., Rhodes, J. E., Silverthorn, N., \& Holloway, B. E (2011). A systematic assessment of the evidence. Psychological Science in the Public Interest. doi:10.1177/ 1529100611414806.

Durlak, J. A., Weissberg, R. P., Dymnicki, A. B., Taylor, R. D., \& Schellinger, K. B. (2011). The impact of enhancing students' social and emotional learning: A meta-analysis of school-based universal interventions. Child Development, 82(1), 405-432.

Edwards, O. W., Mumford, V. E., \& Serra-Roldan, R. (2007). A positive youth development model for students considered at-risk. School Psychology International, 28(1), 29-45.

Grossman, J. B., Chan, C. S., Schwartz, S. E. O., \& Rhodes, J. E. (2012). The test of time in school-based mentoring: The role of relationship duration and re-matching on academic outcomes. American Journal of Community Psychology. doi:10.1007/s10464-011-9435-0. 
Herrera, C., Grossman, J. B., Kauh, T. J., \& McMaken, J. (2011). Mentoring in schools: An impact study of Big Brother Big Sisters school-based mentoring. Child Development, 82(1), 346-361.

Huta, V., \& Ryan, R. M. (2010). Pursuing pleasure or virtue: The differential and overlapping well-Being benefits of hedonic and eudaimonic motives. Journal of Happiness Studies. doi:10.1007/ s10902-009-9171-4.

Karcher, M. J. (2008). The study of mentoring in the learning environment (SMILE). A randomized evaluation of the effectiveness of school-based mentoring. Prevention Science, 9(2), 99-113.

Karcher, M. J., \& Nakkula, M. J. (2010). Youth mentoring with a balanced focus, shared perspective, and collaborative interactions. New Directions for Youth Development. doi:10.1002/yd.

Larson, R. (2006). Positive youth development, willfull adolescents and mentoring. Journal of Community Psychology, 34(6), 677-689.

Lavigne, G. L., Vallerand, R. J., \& Crevier-Braud, L. (2011). The fundamental need to belong: On the distinction between growth and deficit-reduction orientations. Personality and Social Psychology Bulletin, 37(9), 1185-1201.

Levesque, C., Zuehlke, A. N., Stanek, L. R., \& Ryan, R. M. (2004). Autonomy and competence in German and American university students: A comparative study based on self-determination theory. Journal of Educational Psychology, 96, 69-84.

Linley, P. A., Maltby, J., Wood, A. M., Osbourne, G., \& Hurling, R. (2009). Measuring happiness: The higher order factor structure of subjective of psychological well-being measures. Personality and Individual Differences, 47(8), 878-884.

Marques, S. C., Pais-Ribeiro, J. L., \& López, S. H. (2009). Validation of a Portuguese version of the children's hope scale. School Psychology International, 30(5), 538-551.

Milyavskaya, M., Gingras, I., Koestner, R., Gagnon, H., Fang, J., \& Boiché, J. (2009). Balance across contexts: Importance of balanced need satisfaction across various life domains. Personality and Social Psychology Bulletin, 35(8), 1031-1045.

Murray-Harvey, R. (2010). Relationships influences on students' academic achievement, psychological health and well-being at school. Educational and Child Psychology, 27(1), 104-115.

Murray-Harvey, R., \& Slee, P. T. (2006). Australian and Japanese school students' experiences of school bullying and victimization: Associations with stress, support and school belonging. International Journal on Violence and School, 2(1), 33-50.

Pollard, E. L., \& Lee, P. D. (2003). Child well-being: A systematic review of the literature. Social Indicators Research, 61(1), 59-78.

Portwood, S. G., Ayers, P. M., Kinnison, K. E., Waris, R. G., \& Wise, D. L. (2005). YouthFriends: Outcomes from a school-based mentoring program. The Journal of Primary Prevention, 26(2), 129-145.

Randolph, J. J., Kangas, M., \& Ruokamo, H. (2010). Predictors of Dutch and Finnish students' satisfaction with schooling. Journal of Happiness Studies, 11(22), 193-204.

Ravens-Sieberer, U., Auquier, P., Erhart, M., Gosch, A., Rajmil, L., Bruil, J., et al. (2007). The KIDSCREEN-27 quality of life measure for children and adolescents: Psychometric results of a crosscultural survey in 13 European countries. Quality of Life Reearch, 16(8), 1347-1356.

Reis, H. T., Sheldon, K. M., Gable, S. L., Roscoe, J., \& Ryan, R. M. (2000). Daily well-being: The role of autonomy, competence, and relatedness. Personality and Social Psychology Bulletin, 26(4), 419-435.

Roorda, D. L., Koomen, J. L., Spilt, J. L., \& Oort, F. J. (2011). The influence of affective teacher-student relationships on student's school engagement and achievement: A meta-analytical approach. Review of Educational Research, 81(4), 493-529.

Russell, L. (2007). Mentoring is not for you!: Mentee voices on managing the mentoring experience. Improving Schools, 10(1), 41-52.

Rutter, M. (2006). The promotion of resilience in the face of adversity. In A. Clarke-Stewart \& J. Dunn (Eds.), Families count: Effects on child and adolescent development (pp. 26-52). New York, NY, US: Cambridge University Press.

Ryan, R. M., La Guardia, J. G., Sulky-Butzel, J., Chirkov, V., \& Kim, Y. (2005). On the interpersonal regulation of emotions: Emotional reliance across gender, relationships, and cultures. Personal Relationships, 12(1), 145-163.

Schüler, J., Sheldon, K. M., \& Fröhlich, S. M. (2009). Implicit need for achievement moderates the relationship between competence need satisfaction and subsequent motivation. Journal of Research in Personality. doi:10.1016/j.jrp.2009.09.002.

Schwartz, S. E. O., Rhodes, J. E., Chan, E. S., \& Herrera, C. (2011). The impact of SBM on youths with different relational profiles. Developmental Psychology, 47(2), 450-462. 
Simões, F., \& Alarcão, M. (2011). Avaliação da Motivação Intrínseca na Aprendizagem: Validação de Duas Escalas para Crianças e Adolescentes. [Assessment of Intrinsic Motivation for Learning: Validation of Two Scales for Children and Adolescents]. PSICO-USF, 16(3), 265-273.

Simões, F., \& Alarcão, M. (2013a). A Satisfação de Necessidades Psicológicas Básicas em Crianças e Adolescentes: Adaptação e Validação da ESNPBR. [Support of BPN in Children and Adolescents: Adaptation and Validation of the ESNPBR]. Psicologia Reflexão e Crítica. (submitted).

Simões, F., \& Alarcão, M. (2013b). The structure and the process of social support in school-based mentoring: An exploratory study based on the Self-Determination Theory. (submitted).

Vanteenkiste, M., Sierens, E., Soenens, B., Luyckx, E., \& Lens, W. (2009). Motivational profiles from a self-determination perspective: The quality of motivation matters. Journal of Educational Psychology. doi:10.1037/a0015083.

Véroneau, M. H., Koestner, R. F., \& Abela, J. R. Z. (2004). Intrinsic need satisfaction and well-being in children and adolescents: An application of the self-determination theory. Journal of Social and Clinical Psychology, 24(2), 280-292.

Wilson, S., \& Lipsey, M. W. (2007). School-based interventions for aggressive and disruptive behavior: Update of a meta-analysis. American Journal of Preventive Medicine. doi:10.1016/j.amepre. 2007.04 .011 